\title{
Evaluation and modelling of perpendicular to grain embedment strength
}

\author{
J. C. M. Schoenmakers • A. J. M. Jorissen •
}

A. J. M. Leijten

Received: 21 November 2008/Published online: 24 November 2009

(C) The Author(s) 2009. This article is published with open access at Springerlink.com

\begin{abstract}
Different test setups for determining perpendicular to grain embedment strength of timber have been reported in literature. In addition, different definitions of strength have been used associated with the deformation level underneath the fastener. It is shown that all reported experimental results can be related, which enables comparison on a common basis. Furthermore, several models for embedment strength perpendicular to the grain which primarily depend on timber density (specific gravity) and fastener diameter are evaluated. It is shown that the model currently prescribed by the European structural timber design code [Comité Européen de Normalisation (CEN) EN 1995-1-1: 2004: Eurocode 5-design of timber structures. Part 1.1: general rules and rules for buildings. CEN, Brussels, 2004] is unable to accurately predict the strength and an alternative is proposed. This may result in more reliable timber connections in applying the European Yield Model to determine the connection strength.
\end{abstract}

\section{Introduction}

In the past, comprehensive studies on the embedment (bearing) strength of doweltype fasteners have been reported (Leijten et al. 2004; Whale and Smith 1986; Sawata and Yasumura 2002). Both parallel and perpendicular to grain embedment were considered. Embedment strength, $f_{h}$, is commonly defined as the force, $F$, divided by the timber width, $t$, and the fastener diameter, $d$ (Eq. 1).

\footnotetext{
J. C. M. Schoenmakers ( $\square)$

Eindhoven University of Technology, P.O. Box 513,

5600 MB Eindhoven, The Netherlands

e-mail: J.C.M.Schoenmakers@tue.nl
}

\author{
A. J. M. Jorissen - A. J. M. Leijten \\ Timber Structures, Eindhoven University of Technology, \\ P.O. Box 513, 5600 MB Eindhoven, The Netherlands
}




$$
f_{h}=\frac{F}{d t}
$$

Perpendicular to grain embedment strength was determined by using different test setups. In addition, the stress level regarded as being the embedment strength differs. This is due to the hardening behaviour of timber loaded in compression perpendicular to the grain, i.e., after an initial linear (elastic) response the material starts to yield which causes the response to become less stiff. Therefore, the stress level depends on the deformation level. Embedment strength thus is dependent on the embedment displacement (fastener slip) causing the ultimate strength to be governed by the deformation ability of the embedment zone. Several definitions of strength have been used reflecting the stress level reached at or within a certain displacement level. This should be considered when analysing experimental results reported in literature.

Whale and Smith (1986) determined the embedment strength by means of small timber specimens subjected to bending (small-scale bending) (Fig. 1a). Mainly softwood species were tested using nails and bolts with diameters ranging from 2.65 to $20 \mathrm{~mm}$. The specimen geometry was expressed in terms of the fastener diameter where the loaded edge distance, $h_{e}$, for nails and bolts was $4 d$ and $5 d$, respectively, with $d$ as the fastener diameter. Force and embedment displacement (fastener slip) were recorded. The slip was measured by means of displacement transducers measuring the distance between the fastener and the unloaded edge of the specimen. After preliminary tests they decided to define embedment strength as the maximum stress level reached within 2.1-mm slip, as specimens with small diameter nails tend to fail at low slip levels due to premature crack development at the fastener holes. In addition, stiffness parameters modelling the load-slip response by a 3-parameter exponential function were reported. A strong influence of fastener diameter, $d$, and timber density, $\rho$, on the embedment strength was observed.

Sawata and Yasumura (2002) tested full-constrained specimens (continuously supported over the specimen length) (Fig. 1b). The tests were performed in accordance with EN 383 (1993), except for the specimen width which was fixed at $32 \mathrm{~mm}$, and independent of the fastener diameter. This investigation dealt with two commercial Japanese species and bolts with diameters ranging from 8 to $20 \mathrm{~mm}$, respectively. Force and fastener slip were recorded similarly as done by Whale and Smith (1986). Sawata and Yasumura (2002) reported the strength as the maximum stress level reached within 5.0-mm slip, according to the European Standard EN 383

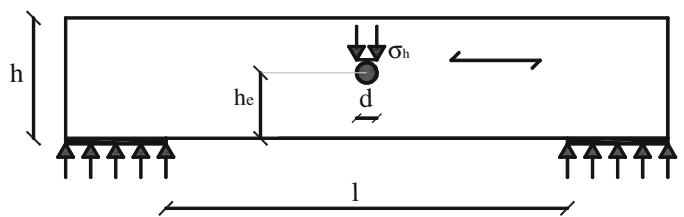

(a)

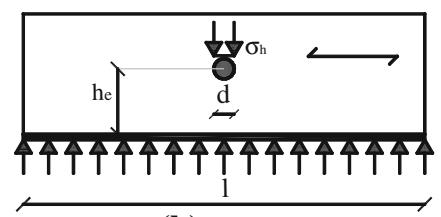

(b)

Fig. 1 Two different experimental setups to determine embedment strength perpendicular to the grain. a Small-scale bending specimen. b Full-constrained specimen 
(1993). They also noticed a significant influence of timber density and fastener diameter and attempted to model the (average) embedment strength perpendicular to the grain, $f_{h ; 90 ; m}$, (at $5 \mathrm{~mm}$ deformation) as a function of these parameters and of the (average) compression strength parallel to the grain, $f_{c ; 0 ; m}$, in an empirical way (Eq. 2), with $\rho$ the measured density

$$
f_{h ; 90 ; m}=(-0.016 d+0.745) f_{c ; 0 ; m} \text {, with } f_{c ; 0 ; m}=0.0973 \rho .
$$

Leijten et al. (2004) and Leijten and Köhler (2004) evaluated embedment tests perpendicular to the grain in a probabilistic framework to enable reliability analyses. Based on multiple linear regression analyses they defined constants that fit the data bases best. Equation 3 was used for this purpose which serves as predictor of the average measured strength.

$$
f_{h ; 90 ; m}=A \rho^{B} d^{C}
$$

Table 1 gives an overview of the constants, $A, B$ and $C$ given by Leijten and Köhler (2004). Different equations have been reported to describe the tests performed by Whale and Smith (1986) dealing with nails and for the tests by Sawata and Yasumura (2002) dealing with bolts. The data corresponding to bolts by Whale and Smith (1986) were discarded from the overall analyses because they were regarded as corrupted.

The current European Standard (Eurocode 5 2004) empirically describes the embedment strength perpendicular to the grain by means of a Hankinsontransformation of the embedment strength parallel to the grain in case of larger dowel-type fasteners like bolts and dowels. For softwoods perpendicular to the grain the equation becomes Eq. 4. In case of nails no dependence of the orientation with respect to the grain is suggested (Eq. 5).

$$
\begin{aligned}
f_{h ; 90 ; k} & =\frac{0.082(1-0.01 d) \rho_{k}}{1.35+0.015 d} \\
f_{h ; 0 ; k} & =f_{h ; 90 ; k}=0.082 d^{-0.3} \rho_{k}
\end{aligned}
$$

In both equations, $\rho_{k}$ and $f_{h ; \alpha ; k},(\alpha=0.90)$ denote the characteristic timber density and strength, respectively.

Van der Put (2008a) applied the equilibrium method of plasticity to the problem of compression perpendicular to the grain of timber sills. In Van der Put (2008b) this theory was applied to explain the embedment strength of nailed particle board, and in Van der Put and Leijten (2000) the method was applied to explain the failure mechanism of timber connections made of one single dowel loading a beam.

Table 1 Overview of average values of constants given by Leijten and Köhler (2004)

\begin{tabular}{lcc}
\hline & Nails (Whale and Smith 1986) & Bolts (Sawata and Yasumura 2002) \\
\hline$A$ & -3.085869 & -2.547059 \\
$B$ & 1.148261 & 1.099235 \\
$C$ & -0.419665 & -0.431719 \\
\hline
\end{tabular}


According to this model the stress below a dowel-type fastener will be distributed through the specimen at a certain angle towards a larger supporting area, similar as is the case for sills (Fig. 2). Van der Put and Leijten (2000) suggest a stress dispersion angle of 1:1.5 which results in Eq. 6 with $h_{e}$ the loaded edge distance and $f_{c ; 90 ; m}$ the standard compressive strength perpendicular to the grain. Equation 6 shows a positive influence of the loaded edge distance, which results in higher embedment strengths.

$$
f_{h ; 90 ; m}=f_{c ; 90 ; m} \sqrt{\frac{3 h_{e}}{d}}
$$

This paper considers some additional experiments and thorough analyses of existing data bases, which enables to describe the embedment perpendicular to the grain more accurately. Furthermore, a relation among both experimental methods, i.e., small-scale bending or full-constrained specimen, shall be discussed.

\section{Experiments}

Materials and methods

The mechanics in either small-scale bending or full-constrained specimens differs as a result of the constraints applied at either the ends or at the full specimen length. Figure 3 shows the result of two simple finite element models of both setups with respect to the direction and size of the principle stresses and the perpendicular to the grain stresses. Analyses were performed with the commercial FE-package ABAQUS v6.7. The timber was modelled using quadratic elements with linear elastic orthotropic properties. The load was applied as a uniformly distributed conservative load. Analyses were not aimed at an accurate description of the real structural behaviour, but to visualize the differences in mechanical behaviour.

In case of full-constrained specimen, the principle directions of stress are mainly parallel and perpendicular to the loading direction and concentrated at the fastener hole. This indicates that embedment is a very local phenomenon. The (compressive) stresses perpendicular to the grain are very high just beneath the fastener and are dispersed through the specimen. The overall stiffness of the specimen and the constraints cause material far away from the hole to be activated and to contribute to the load-bearing capacity.
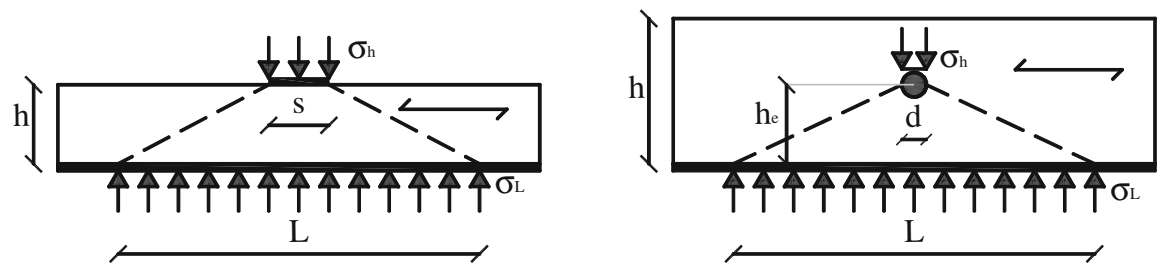

Fig. 2 Analogy among compressive strength test and embedment strength test 

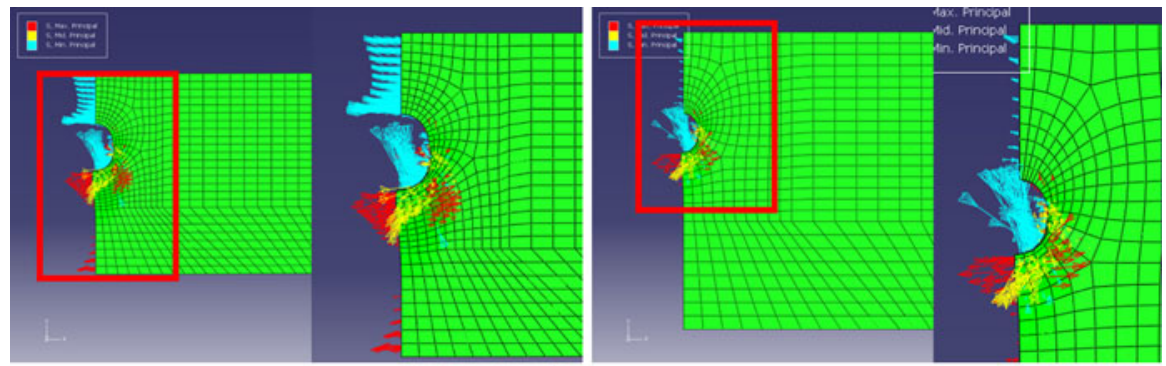

Direction and size of principle stress
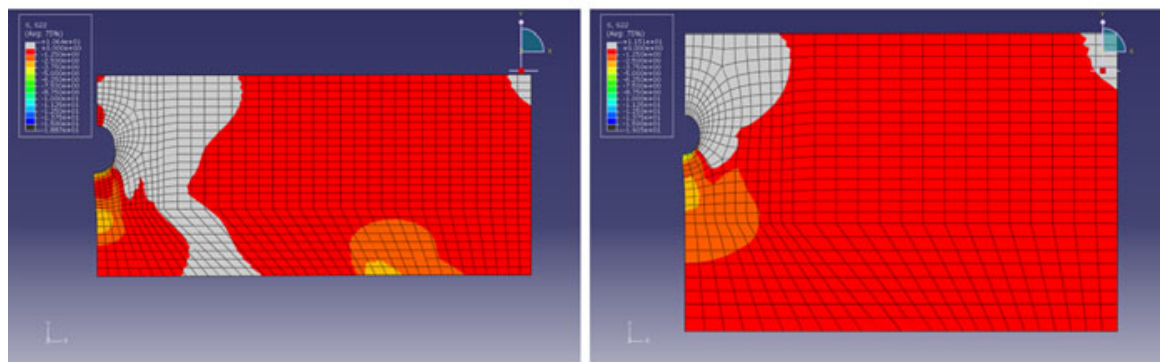

Compressive stress perpendicular to grain

Small-scale bending

Full-constrained

Fig. 3 Comparison of experimental setup regarding principle and perpendicular to grain stresses (compressive only). Left small-scale bending, right full-constrained

In case of small-scale bending specimens, a bending-tensile and bendingcompressive zone will develop with stresses that may become relatively high, indicated by the arrows of principle directions and stresses. It is likely that these stresses show some interaction with the perpendicular to grain embedment stresses. The bending stresses also cause less material to be activated far away from the fastener hole.

Experiments were performed on both small-scale bending and full-constrained specimens with two different dowel diameters, 8 and $16 \mathrm{~mm}$, respectively, at varying loaded edge distances. The timber species used was Picea abies with an average density of $450 \mathrm{~kg} / \mathrm{m}^{3}$ and a moisture content of $\omega=12.7 \%$, which prior to testing was conditioned to constant mass in a constant climate at an average temperature of $T=20^{\circ} \mathrm{C}$ and a relative humidity of $66 \%$ which is in the allowable range according to EN 383 (1993). Table 2 gives an overview of the specimen dimensions and applied setup. Each series consists of five replicates (except one full-constrained series indicated by code FCB consisting of ten replicates), which is considered sufficient to obtain information on general trends in behaviour. During the tests the deformation was measured at the unloaded edge, while the load was applied at a constant rate of displacement.

These experiments aimed at investigating the influence of the loaded edge distance, as suggested by Van der Put and Leijten (2000), at comparing both experimental setups as the mechanics is rather different, and at determining the 
Table 2 Overview of experiments (see also Fig. 1)

\begin{tabular}{|c|c|c|c|c|c|}
\hline Series (-) & $\begin{array}{l}\text { Diameter } \\
(\mathrm{mm})\end{array}$ & $\begin{array}{l}\text { Loaded edge } \\
\text { distance }(\mathrm{mm})\end{array}$ & $\begin{array}{l}\text { Length/span } \\
(\mathrm{mm})\end{array}$ & $\begin{array}{l}\text { Height } \\
(\mathrm{mm})\end{array}$ & Setup (-) \\
\hline SCB-16-2d & 16 & $2 d$ & $16 d$ & $6 d$ & Fig. 1a \\
\hline SCB-16-3d & 16 & $3 d$ & $16 d$ & $6 d$ & Fig. 1a \\
\hline SCB-16-4d & 16 & $4 d$ & $16 d$ & $6 d$ & Fig. 1a \\
\hline FCA-16-3d & 16 & $3 d$ & $12 d$ & $6 d$ & Fig. 1b \\
\hline FCA-16-4d & 16 & $4 d$ & $12 d$ & $6 d$ & Fig. 1b \\
\hline FCB-16-2d & 16 & $2 d$ & 300 & 150 & Fig. 1b \\
\hline FCB-16-3d & 16 & $3 d$ & 300 & 150 & Fig. 1b \\
\hline FCB-16-4d & 16 & $4 d$ & 300 & 150 & Fig. 1b \\
\hline FCB-16-5d & 16 & $5 d$ & 300 & 150 & Fig. 1b \\
\hline FCB-16-6d & 16 & $6 d$ & 300 & 150 & Fig. 1b \\
\hline SCB-8-1d & 8 & $1 d$ & $16 d$ & $6 d$ & Fig. 1a \\
\hline SCB-8-2d & 8 & $2 d$ & $16 d$ & $6 d$ & Fig. 1a \\
\hline SCB-8-3d & 8 & $3 d$ & $16 d$ & $6 d$ & Fig. 1a \\
\hline SCB-8-4d & 8 & $4 d$ & $16 d$ & $6 d$ & Fig. 1a \\
\hline SCB-8-5d & 8 & $5 d$ & $16 d$ & $6 d$ & Fig. 1a \\
\hline FCA-8-2d & 8 & $2 d$ & $16 d$ & $6 d$ & Fig. 1b \\
\hline FCA-8-4d & 8 & $4 d$ & $16 d$ & $6 d$ & Fig. 1b \\
\hline
\end{tabular}

Timber width $t=2 d$ in all cases

Denomination of specimens: \#-n-m

\#: Specimen setup (small-scale bending (SCB), full-constrained A (FCA) and full-constrained B (FCB))

n: Fastener diameter

$\mathrm{m}$ : Loaded edge distance expressed in terms of $d$

influence of fastener diameter. Comparison of experimental setups is performed using specimens with equal geometrical properties.

\section{Results}

Figure 4 shows some typical load-slip responses. From this figure it can be seen that each response can accurately be represented by a bi-linear approximation (dashed lines), defined by only three pairs of slip-stress values (coordinates), thus enabling a simplified comparison methodology. The values thus define the initial point $(0,0)$, the onset of yielding, $\left(u_{y}, \sigma_{y}\right)$ and the maximum, $\left(u_{u}, \sigma_{u}\right)$. These results are summarized in Table 3. In addition, the stress levels associated with 2.1 and $5.0 \mathrm{~mm}$ slip, $\sigma_{2.1 \mathrm{~mm}}$ and $\sigma_{5.0 \mathrm{~mm}}$, are given. Graphically, the results are depicted in Figs. 5 and 6. In the latter figure the gray lines (both dashed and continuous) represent the results obtained from small-scale bending specimens, Fig. 1a, the black lines (both dashed and continuous) correspond to specimens of Fig. $1 \mathrm{~b}$.

Comparison of the load-slip response of full-constrained specimens with equal dimensions and altered loaded edge distance (code FCB-16-n-m) shows no significant differences in stiffness nor does the embedment stress at given deformations (Fig. 5). 


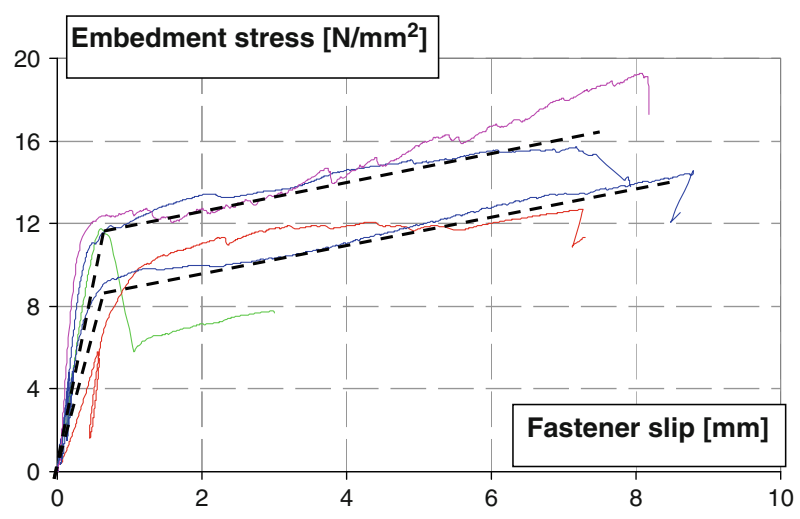

Fig. 4 Some typical load-slip responses

Fig. 5 Approximation of the response per test series (FCB)

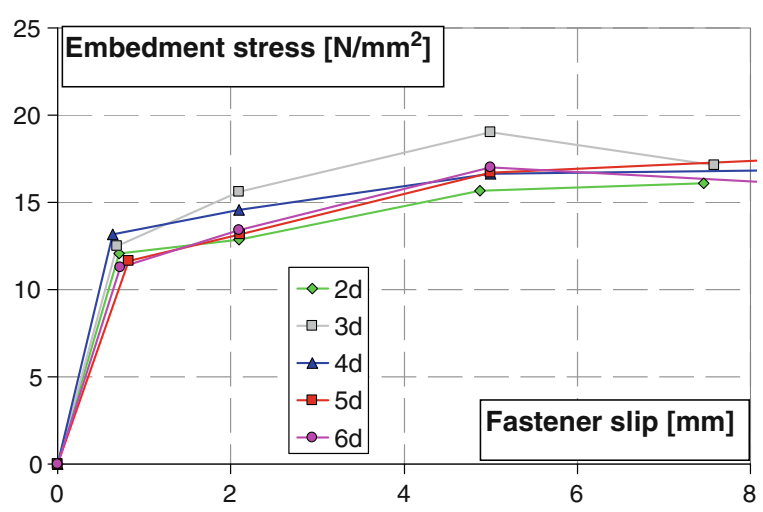

Therefore, it can be concluded that embedment stress is not affected by the loaded edge distance suggesting that embedment strength is a local phenomenon.

From Fig. 6 it can be seen that the embedment stress at a given deformation is highest for the 8-mm diameter fasteners, although these fasteners cannot generate as much slip as the 16-mm fasteners can, i.e., the timber cannot sustain the same deformation. Regarding stiffness, it appears that $8-\mathrm{mm}$ fasteners behave slightly stiffer than the 16-mm fasteners up until yielding. This initial stiffness seems not to be affected by the test setup used. The tangent modulus of the hardening branch appears to be steepest for the 8-mm fasteners, although no test on significance has been performed. This modulus, however, is also affected by the test setup as the full-constrained specimens generate stronger hardening.

Comparing the influence of the loaded edge distance in Fig. 6 shows that this parameter affects the load-slip response slightly in both setups. From Table 3 for instance, series SCB-16-3d and SCB-16-4d an increase in loaded edge distance of $16 \mathrm{~mm}(1 d)$ causing an increase in measured embedment stress of approximately $5 \%$ at given deformations is observed. Similar strength increases are observed by regarding the small-scale bending specimens with 8 -mm diameter fasteners. 


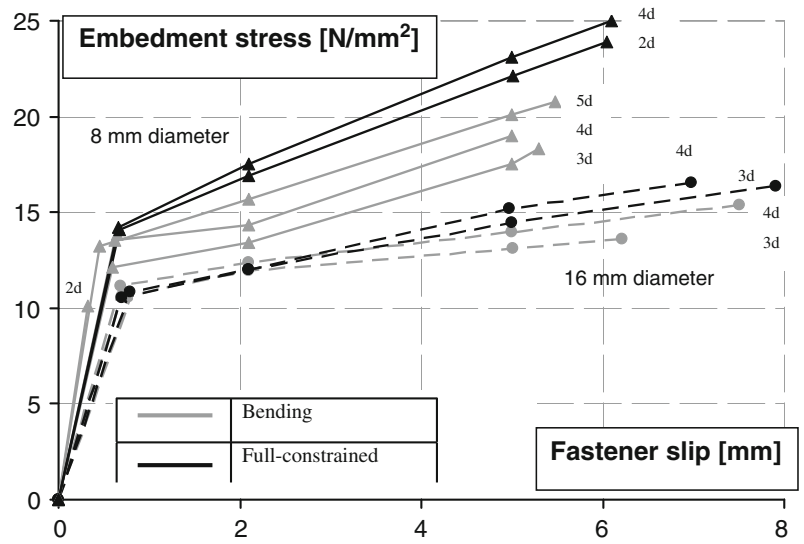

Fig. 6 Approximation of the response per test series (SCB and FCA)

Table 3 Experimental results defined by stress levels at certain slip values

\begin{tabular}{lllllll}
\hline Series $(-)$ & $u_{y}(\mathrm{~mm})$ & $\sigma_{y}\left(\mathrm{~N} / \mathrm{mm}^{2}\right)$ & $\sigma_{2.1 \mathrm{~mm}}\left(\mathrm{~N} / \mathrm{mm}^{2}\right)$ & $\sigma_{5 \mathrm{~mm}}\left(\mathrm{~N} / \mathrm{mm}^{2}\right)$ & $u_{u}(\mathrm{~mm})$ & $\sigma_{u}\left(\mathrm{~N} / \mathrm{mm}^{2}\right)$ \\
\hline SCB-16-2d & 0.794 & 10.47 & & & & \\
SCB-16-3d & 0.70 & 10.62 & 11.97 & 13.14 & 6.21 & 13.61 \\
SCB-16-4d & 0.69 & 11.15 & 12.35 & 13.99 & 7.50 & 15.39 \\
FCA-16-3d & 0.78 & 10.86 & 11.99 & 14.48 & 7.92 & 16.36 \\
FCA-16-4d & 0.70 & 10.52 & 12.02 & 15.17 & 6.98 & 16.53 \\
FCB-16-2d & 0.71 & 12.10 & 12.85 & 15.64 & 7.46 & 16.11 \\
FCB-16-3d & 0.68 & 12.50 & 15.60 & 19.00 & 7.59 & 17.14 \\
FCB-16-4d & 0.64 & 13.20 & 14.56 & 16.62 & 8.12 & 16.86 \\
FCB-16-5d & 0.82 & 11.64 & 13.20 & 13.93 & 8.55 & 14.59 \\
FCB-16-6d & 0.72 & 11.30 & 13.44 & 17.04 & 8.18 & 16.17 \\
SCB-8-1d & 0.33 & 10.11 & 0.00 & 0.00 & 0.33 & 10.11 \\
SCB-8-2d & 0.65 & 13.82 & 0.00 & 0.00 & 0.65 & 13.82 \\
SCB-8-3d & 0.62 & 13.52 & 14.36 & 0.00 & 5.00 & 19.00 \\
SCB-8-4d & 0.60 & 12.12 & 13.44 & 17.50 & 5.30 & 18.30 \\
SCB-8-5d & 0.45 & 13.26 & 15.71 & 20.08 & 5.48 & 20.78 \\
FCA-8-2d & 0.68 & 14.08 & 16.89 & 22.11 & 6.05 & 23.90 \\
FCA-8-4d & 0.66 & 14.24 & 17.50 & 23.10 & 6.10 & 25 \\
\hline
\end{tabular}

The influence of the loaded edge distance obtained from Figs. 5 and 6 is contrasting. Because Fig. 5 shows random results with respect to the loaded edge distance, and because this chart is based on ten replicates per series, it is likely that the positive influence shown in Fig. 6 with respect to the full-constrained specimens is caused by natural variations in timber properties. This implies that the model 
proposed by Van der Put and Leijten (2000) is not able to describe the results accurately. However, due to the interaction of bending stresses and embedment stresses in case of small-scale bending specimens, it is likely that an increase in loaded edge distance indeed results in higher embedment stresses. This may be caused by the bending-compressive stresses which may act as pre-stressing effect in case of high loaded edge distances, and bending-tensile stresses which apparently reduce the strength in case of small loaded edge distances. In this respect the bending stresses will have a negative (compression zone) or a positive influence (tension zone) on the failure criterion which therefore is met later or earlier in terms of embedment stress. Although this test setup does not enable pure measurements of the embedment strength, it likely provides a better representation of the behaviour of real structures with dowel-type fasteners compared to the full-constrained setup. After all, the majority of timber connections are used in beams or columns, i.e., with the interaction of bending stresses.

In case of small-scale bending specimens, the loaded edge distance should be $3 d$ at least for $16-\mathrm{mm}$ fasteners and $4 d$ for $8-\mathrm{mm}$ diameters in order to prevent premature crack development, and thus limiting the ability to fully develop the embedment mechanism. All specimens from which a strong hardening response was recorded developed cracks at the holes as well as severe crushing zones.

\section{Analyses of experiments}

This section describes some analyses of experimental results presented in the previous chapter as well as the results reported in literature.

Whale and Smith (1986) have reported on experiments on Pinus sylvestris loaded by nine different fastener diameters, each series consisting of 20 replicates (Fig. 8). This figure also shows an increase in embedment strength with decreasing fastener diameter suggesting a size effect.

\section{Determination of the size effect}

A size effect generally can be accounted for by means of Weibull's weakest link theory. This theory has been successfully adopted to model timber loaded in tension perpendicular to the grain. Shear failure in timber shows a size effect as well. Size effects for timber loaded in compression do not exist to the authors' knowledge. At the micro scale, timber loaded in compression will show cracks even at rather low stress levels. Crack development underneath the fasteners seems necessary in order to redistribute stresses and allow large deformations. This justifies adoption of the method to this problem. The theory assumes that the likelihood of the existence of defects like knots, micro-cracks and voids is larger for larger specimen volumes. Such defects are likely to influence the load-bearing capacity. Equation 7 represents the relationship between two strengths and their respective volumes having the same (statistical) probability of failure. 


$$
f_{1}=f_{2}\left(\frac{V_{2}}{V_{1}}\right)^{\frac{1}{k}}
$$

In this equation $V_{2}$ and $f_{2}$ are the volume and strength of the so-called reference volume, and $V_{1}$ and $f_{1}$ correspond to the specimen investigated and $k$ being the shape factor of the Weibull distribution. The volumes, $V=t h d$, can be expressed in terms of fastener diameters as $V=\xi d \eta d d$, where $\xi$ and $\eta$ normalize the width and height of the volume with respect to the diameter, $d$. It can be assumed that an increase in fastener diameter is associated with a proportional increase of the width and height of the volume, i.e., $\xi$ and $\eta$ are constants (similar to the ones in a loupe). The volume effect thus can be written as:

$$
f_{1}=f_{2}\left(\frac{\xi d_{2} \eta d_{2} d_{2}}{\xi d_{1} \eta d_{1} d_{1}}\right)^{\frac{1}{k}} \Rightarrow f_{1}=f_{2}\left(\frac{d_{2}}{d_{1}}\right)^{\frac{3}{k}} .
$$

Series expansion of the gamma functions defining the square coefficient of variation (square of the ratio of the standard deviation and the average) of the Weibull distribution shows that the coefficient of variation, $s / \mu$, is a nearly constant function in the region with $k \approx 4$ and beyond (Eq. 9) (Van der Put and Leijten 2000).

$$
\left(\frac{s}{\mu}\right)^{2}=\frac{\Gamma(1+2 / k)}{\Gamma^{2}(1+1 / k)}-1 \Rightarrow \frac{s}{\mu}=\sqrt{\frac{\Gamma(1+2 / k)}{\Gamma^{2}(1+1 / k)}-1} \approx \frac{1.2}{k}
$$

Figure 7 shows the influence of the shape factor $k$ on the coefficient of variation from which it is noticed that $s k / \mu$ has a minimum of $s k / \mu=1$, if $k=1$. Van der Put (2008b) implicitly assumes that in reality $k>4$ by taking $s k / \mu=1.2$, and $s / \mu=20 \%$, i.e., $k=6$. With these values it follows with Eq. 8:

$$
f_{1}=f_{2}\left(\frac{d_{2}}{d_{1}}\right)^{\frac{3}{1.2} \frac{s}{\mu}}=f_{2}\left(\frac{d_{2}}{d_{1}}\right)^{\frac{3 \cdot 0.2}{1.2}}=f_{2} \sqrt{\frac{d_{2}}{d_{1}}} .
$$

Application to the problem considered here implies that $f_{1}$ is the embedment strength corresponding to a diameter $d_{1}$, etc. Although the coefficient of variation $s / \mu$ applied here corresponds to the Weibull model, the materials coefficient of variation can reasonably be adopted in this respect instead. Commonly observed variation in mechanical properties of timber are in the range of $20 \%$ which justifies the assumption made by Van der Put (2008b).

Figure 8 shows the prediction ability of Eq. 10 as well as a best power regression line based on a least square approximation for test results reported by Whale and Smith (1986) on P. sylvestris. Equation 10 represents a power approximation with power 0.5 which is based on phenomenological considerations. The regression line is found with an overall power of 0.55 , instead of 0.5 (Fig. 8). The power $3 / k=0.55$ is an empirical estimate. The difference between both predictions is relatively small and can be explained by the stochastic nature of timber. Another explanation can be given by considering Fig. 8 for small nails for which the difference becomes apparent. This is caused by the fact that the embedment strength of a bolt with $d_{2}=12 \mathrm{~mm}$, i.e., $f_{h ; 90 ; 12 \mathrm{~mm}}=14.77 \mathrm{~N} / \mathrm{mm}^{2}$ was taken as the 


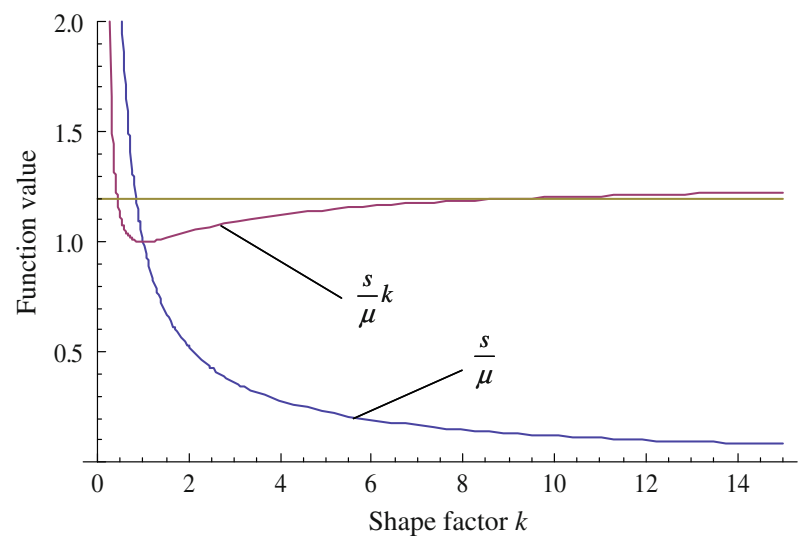

Fig. 7 Influence of shape factor $k$ on the coefficient of variations

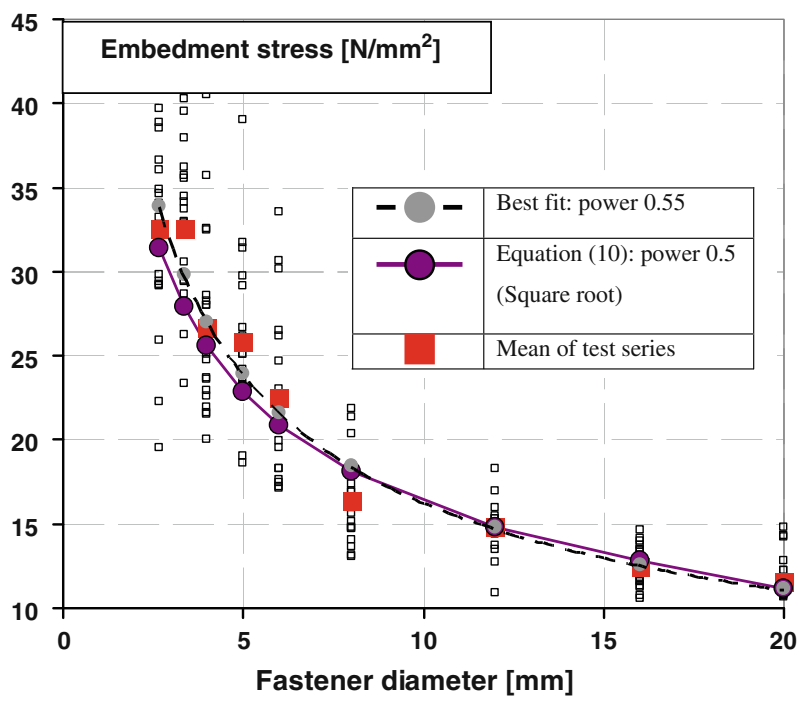

Fig. 8 Experimental results of Pinus sylvestris and analytical expressions

reference. Apparently, small nails show a stronger size effect which may be caused by their failure mechanism which is not as ductile as in case of larger fasteners. Whale and Smith (1986) observed premature cracking for small nails as well. However, Eq. 10 is still able to predict the strength values rather accurately with exception for the results of fasteners with diameters of $3.35,5$ and $8 \mathrm{~mm}$, respectively, which obviously deviate from the general trend.

Influence of timber density

Equation 10 has been calibrated with experiments performed on $P$. sylvestris with an average timber density of $455 \mathrm{~kg} / \mathrm{m}^{3}$, corrected for standardized climatic 
Table 4 Comparison of Eq. 11 and test results reported by Whale and Smith (1986) (test/prediction)

\begin{tabular}{llllllllll}
\hline Diameter (mm) & 2.65 & 3.35 & 4 & 5 & 6 & 8 & 12 & 16 & 20 \\
Sitka spruce & 1.10 & 1.14 & 1.10 & 1.20 & 1.10 & 0.93 & 0.86 & 1.03 & 1.08 \\
Scots pine & $\mathrm{x}$ & 1.14 & $\mathrm{x}$ & $\mathrm{x}$ & 1.10 & $\mathrm{x}$ & 1.03 & $\mathrm{x}$ & 1.04 \\
Eur. redwood & 1.03 & 1.15 & 1.05 & 1.13 & 1.08 & 0.90 & 1.01 & 0.98 & 1.00 \\
Eur. whitewood & $\mathrm{x}$ & 1.07 & $\mathrm{x}$ & $\mathrm{x}$ & 1.11 & $\mathrm{x}$ & 0.94 & $\mathrm{x}$ & 0.97 \\
Can. spr. pine fir & $\mathrm{x}$ & 1.03 & $\mathrm{x}$ & $\mathrm{x}$ & 1.23 & $\mathrm{x}$ & 1.04 & $\mathrm{x}$ & 0.83 \\
\hline
\end{tabular}

conditions (Leijten and Köhler 2004). As is the case for all mechanical properties of timber, it can be reasonably assumed that density has a positive influence on the embedment strength. This is confirmed by previously mentioned investigations. In accordance with the current Eurocode 5 (2004) it may be assumed that embedment strength perpendicular to the grain is a monotonic function of timber density. Equation 10 thus can be rewritten to take account of different densities. Based on the earlier stated reference strength $f_{2}=f_{h ; 90 ; 12 \mathrm{~mm}}=14.77 \mathrm{~N} / \mathrm{mm}^{2}$ for fasteners of $d_{2}=12 \mathrm{~mm}$ it yields:

$$
f_{1}=f_{2} \sqrt{\frac{d_{2}}{d_{1}}}=f_{h ; 90 ; \mathrm{m}}=14.77 \sqrt{\frac{12}{d}} \times \frac{\rho}{455} .
$$

Equation 11 can obviously be simplified but this is not performed here to show its structure.

Whale and Smith (1986) reported on experiments on several softwood species whose densities ranged from $388 \mathrm{~kg} / \mathrm{m}^{3}$ for Sitka spruce to $481 \mathrm{~kg} / \mathrm{m}^{3}$ for Scots pine. Comparison of Eq. 11 and all test results shows an overall prediction ability of $1.05(\mathrm{COV}=8.9 \%)$ calculated as the test result divided by the model prediction, as can be found in Table 4. Equation 11 predicts the embedment strength rather accurately as indicated by the COV, while the overall prediction ability is safely indicated by the ratio between test and model. From this table it is also noticed that test results on Canadian spruce pine fir deviate most which may indicate that Canadian spruce species behaves slightly different as a result of environmental origin.

\section{Deformation limits}

Equation 11 is shown to be able to describe the embedment strength if the embedment deformation is set to $2.1 \mathrm{~mm}$ (or in certain cases even lower). As a result of the strain hardening behaviour, it can be noticed that the strength at $5.0 \mathrm{~mm}$ slip deformation is higher, see also Fig. 6, with respect to the approximately linear post-elastic branch. Sawata and Yasumura (2002) stated that embedment strength definitions at $2.1-\mathrm{mm}$ slip result in conservative predictions. This conclusion obviously is the result of their testing program containing only bolts of $12 \mathrm{~mm}$ diameter and higher.

The stiffness parameter reported by Whale and Smith (1986) enables an extrapolation of the curves to $5 \mathrm{~mm}$ deformation resulting in a fictitious embedment 
strength as if the deformation was $5 \mathrm{~mm}$, instead of $2.1 \mathrm{~mm}$ or even smaller. This extrapolation shows an embedment strength ratio of $f_{h ; 90 ; 5.0 \mathrm{~mm}} / f_{h ; 90,2.1 \mathrm{~mm}}$ of 1.47 . Multiplying Eq. 11 with this ratio results in the fictitious embedment strength at 5-mm deformation for small-scale bending specimens, Eq. 12:

$$
f_{h ; 90 ; \mathrm{m} ; 5.0 \mathrm{~mm}}=1.47 \cdot 14.77 \sqrt{\frac{12}{d}} \times \frac{\rho}{455} .
$$

Figure 9 shows the prediction ability of Eqs. 11 and 12. Based on this figure it can be concluded that the multiplication factor relates both experimental databases showing that both experimental setups are comparable. From a scientific point of view, the test method used to determine the embedment strength of timber perpendicular to the grain is of no relevance because the results obtained are very much comparable at fixed fastener slip levels. In this respect, it looks like smallscale bending specimens tend to be able to generate an increasing slip with increasing loaded edge distance. This phenomenon should be investigated in the future.

Regarding the test setup it also means that the deformation of the timber in the embedded zone as local phenomenon is governing the load-slip response and thus the ultimate strength which apparently is not (significantly) related to the constraints enforced. Although differences were observed in the analyses of new experiments presented in this paper in the range of 5\%, these differences appear to be of minor importance when experiments from literature are compared.

\section{Model predictions}

This section compares the models of the embedment strength perpendicular to the grain derived by the authors, i.e., Eqs. 11 and 12, and the models found in literature (Eqs. 2-5). The model applied by Van der Put and Leijten (2000) can be discarded

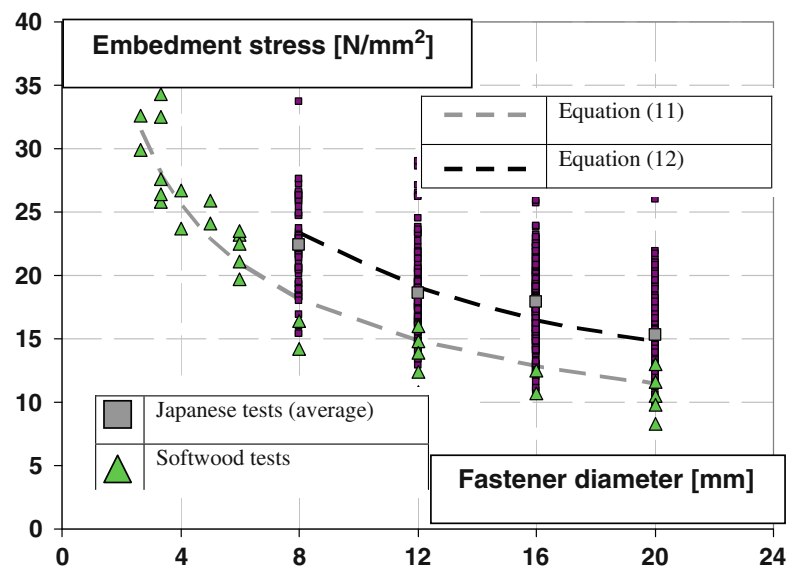

Fig. 9 Prediction ability of Eqs. 11 and 12 
because the suggested strength increase as a result of an increase in loaded edge distance is not in accordance with the observations and thus does not apply for embedment. Because these models are all based on two different data sets, each will be discussed separately.

Data base small-scale bending specimens (UK)

Figure 10 compares Eqs. 3, 5 and 11 with the experiments reported by Whale and Smith (1986) for nails on specimens with an average density of $\rho=426 \mathrm{~kg} / \mathrm{m}^{3}$. This value has also been substituted as the characteristic timber density, $\rho_{k}$, for the Eurocode 5-equations. In this respect it is assumed that inserting an average value for the timber density, an average value for the strength, $f_{h}$, is obtained. From this chart it can be concluded that the Eurocode 5 underestimates the measurements considerably. The equation presented in this paper tends to be on the safe side, while the best predictor appears to be Eq. 3 with the coefficients given in Table 1. The reason why Eq. 11 tends to be safe is discussed earlier and can be explained by an apparent stronger size effect for small fasteners (nails).

Data base full-constrained specimens (Japan)

Figure 11 compares the test data reported by Sawata and Yasumura (2002) as well as the calculated fictitious embedment strengths and Eqs. 2-4, and 12. The density is now based on the Japanese species with $\rho=395 \mathrm{~kg} / \mathrm{m}^{3}$. From this figure it is noticed that the equation by Sawata and Yasumura (2002) slightly overestimates their own results. Regarding the other experiments, no significant differences occur.

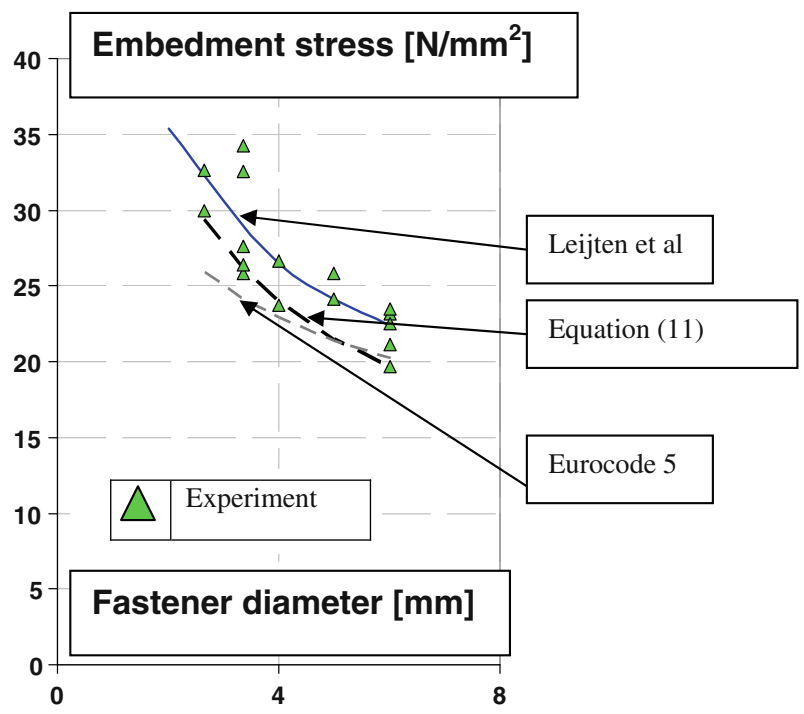

Fig. 10 Model prediction versus tests for nails (Whale and Smith 1986) 


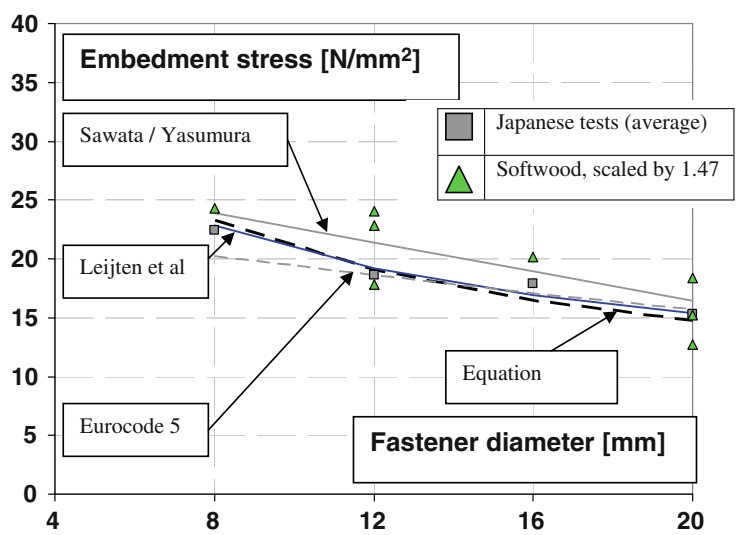

Fig. 11 Model prediction versus tests for bolts (Sawata and Yasumura 2002), and fictitious (extrapolated) strength (Whale and Smith 1986)

Data base new experiments in this paper

Figure 12 compares the proposed model (Eq. 12) with experimental results presented in this paper at deformation levels of 2.1 and $5.0 \mathrm{~mm}$. From this figure it is concluded that the model considerably overestimates the embedment strength corresponding to $5.0-\mathrm{mm}$ deformation in most cases. This indicates that the strain hardening branch in the load-slip behaviour was not as steep as in the experiments by Whale and Smith (1986), i.e., the factor 1.47 should be smaller. The overestimation of strength for dowels $d=8 \mathrm{~mm}$ at 2.1-mm deformation was also observed for the experiments by Whale and Smith (1986) indicating that the strength is generally overestimated for $8-\mathrm{mm}$ diameter fasteners, although this

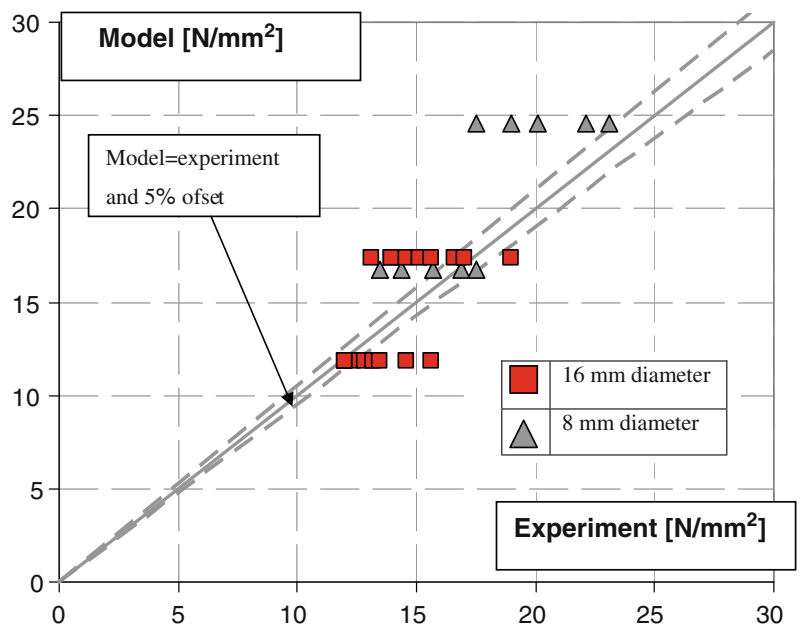

Fig. 12 Model prediction versus tests presented in this paper 
overestimation lies in an acceptable range. This may be felt necessary to be corrected in further work, which is in hand.

\section{Conclusion}

This paper addresses experimental data concerning embedment strength perpendicular to the grain from literature as well as some new experiments. Embedment strength appears to be governed by the deformation level of the timber underneath the dowel-type fastener as a result of hardening. In addition, a new model based on Weibull's weakest link theory is derived which intends at predicting the embedment strength perpendicular to the grain. Parameters affecting the strength are fastener diameter and timber density.

Although different types of experiments for determining embedment strength have been reported by Whale and Smith (1986) and Sawata and Yasumura (2002), it is shown that the results obtained by both methods (small-scale bending and fullconstrained specimens) can be related by means of a simple multiplication factor taking into account the slip of the fastener. Stress analyses by means of the finite element method show that differences in mechanical behaviour among fullconstrained and small-scale bending specimens might be expected as a result of direction and size of the principle stresses. In this respect it is likely that the behaviour of small-scale bending specimens is more related to real timber structural details because of the interaction with bending stresses. Evaluation of new test results shows that full-constrained specimens have slightly higher embedment strengths (at a given deformation) compared to small-scale bending specimens. The hardening branch appears to be steeper as well (but not significantly), indicating that highest stress levels can be obtained using full-constrained specimens. Furthermore, the onset of yielding is only affected by the fastener diameter and independent of all other parameters.

In general, model predictions for embedment strength deviate significantly from experimental results. The model proposed in this paper is able to predict the embedment strength at deformation levels of approximately $2.1 \mathrm{~mm}$ in all cases but tend to overestimate the strength at $5.0-\mathrm{mm}$ deformation, especially in case of $8-\mathrm{mm}$ diameter fasteners. Based on the evaluation of test results and the discrepancies in observed behaviour, some modifications have to be made to the model to become more accurate; this, however, is in hand.

Eurocode 5 is not able to describe experimental results accurately. Generally, the embedment strength is underestimated, although in certain cases even an overestimation occurs. This aspect should be corrected in future guidelines for building practice. Besides, the current Eurocode 5 prescribes two different equations for embedment strength, dependent on the type and size of the fastener. Obviously, small nail diameters show a stronger size effect compared to large dowels and bolts. Evaluation of tests shows that two different equations are not necessary.

The model by Van der Put (2008a) is not able to predict embedment strength perpendicular to the grain because the strong influence of the loaded edge distance is not (significantly) observed in the experiments analysed. Small-scale bending 
specimens tend to show higher stress levels at given deformations as well as larger absolute slip levels. It is possible that this behaviour is not caused by the stochastic nature of timber, but that it truly is a feature of this experimental setup but not detectable as the absolute alterations in loaded edge distances is small. Performing similar tests of full-scale beam elements may provide the information necessary to make a proper statement. This is in hand at the moment.

If full-scale beams loaded by one dowel do show an increase in ultimate strength associated with high slip levels as a result of an increase in loaded edge distance, this may be taken into account in future codes. From an engineering point of view, it is interesting to know such deformation abilities of timber in the embedment zone as it governs the ultimate strength. Higher allowable embedment strengths result in higher load-bearing capacities calculated with the European Yield Model embodied in Eurocode 5. This will benefit the entire timber engineering building practice.

Acknowledgments The authors wish to acknowledge the financial support from the Dutch Technology Foundation STW, applied science division of NWO and the Technology Program of the Ministry of Economic Affairs.

Open Access This article is distributed under the terms of the Creative Commons Attribution Noncommercial License which permits any noncommercial use, distribution, and reproduction in any medium, provided the original author(s) and source are credited.

\section{References}

Comité Européen de Normalisation (CEN) (1993) EN 383: Timber structures. Test methods. Determination of embedding strength and foundation values of dowel type fasteners. CEN, Brussels

Comité Européen de Normalisation (CEN) (2004) EN 1995-1-1: 2004: Eurocode 5-design of timber structures. Part 1.1: general rules and rules for buildings. CEN, Brussels

Leijten AJM, Köhler J (2004) Evaluation of embedment strength data for reliability analyses of connections with dowel type fasteners. Final report of Short Scientific Mission, COST Action E24

Leijten AJM, Köhler J, Jorissen AJM (2004) Review of probability data for timber connections with dowel-type fasteners. Proceedings of CIB-W18/paper 37-7-12, Edinburgh, Scotland

Sawata K, Yasumura M (2002) Determination of embedding strength of wood for dowel-type fasteners. J Wood Sci 48:138-146

Van der Put TACM (2008a) Derivation of the bearing strength perpendicular to the grain of locally loaded timber blocks. Holz Roh Werkst 66:409-417

Van der Put TACM (2008b) Explanation of the embedding strength of particle board. Holz Roh Werkst 66:259-265

Van der Put TACM, Leijten AJM (2000) Evaluation of perpendicular to grain failure of beams caused by concentrated loads of joints. In: Proceedings of CIB-W18/paper 33-7-7, Delft, The Netherlands

Whale LRJ, Smith I (1986) Mechanical joints in structural timberwork-information for probabilistic design. Timber Research and Development Association, Buckinghamshire, England 